添字

$c$ ：吹き出し気体の最初に持っている值， $r$ : 壁面断熱のときの值， $\quad w$ : 壁面のところの値， $\quad x$ : $x$ のところの値，

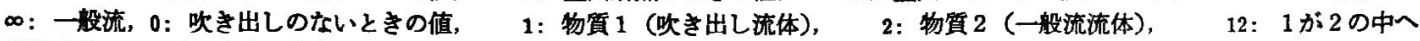
払散する，上つき*：基準温度 $T^{*}=T_{\infty}+0.5\left(T_{w}-T_{\infty}\right)+0.22\left(T_{r}-T_{\infty}\right)$ に対する値。

文赫

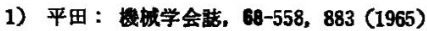

2) Gross, J. F. : et al.: Int. J. Heat Mass Transfer, 3-3, 198 (1961)

3) Baron, J. R.: ARS J., 32-7, 1053 (1962)

4) Sparrow, E. M., et al.: Trans. ASME, Ser. C., 86-3, 311 (1964)

5) Tewfik, O. E.: Int. J. Heat Mass Transfer, 7-4, 409 (1964)

6) Sparrow, E. M. et al.: Trans. ASME, Ser. C, 86-4, 508 (1964)

7) Sparrow, E.M., et al.: AIAA J., 2-4, 652 (1964)

8) Gollnick, A. F.: Int. J. Heat Mass Transfer, 7-7, 699 (1964)

9) Sparrow, E. M, et al.: Trans, ASME, Ser. C, 87-3, 321 (1965)

10) Sparrow, E. M- et al.: AIAA $J_{,}, 3-7,1341$ (1965)

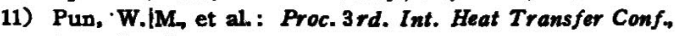
3, 15 (1966)

12) Hirschfelder, J. $\mathrm{O}$, et al.: "Molecular Theory of Gases and Liquids", 68, John Wiley \& Sons, Inc., New York (1954)

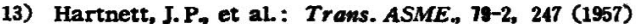

14) Sparrow, E. M, et al. : Int. J. Heat Mass Transfer, 9-1, 53 (1966)

15) Stewart, W.E., et al.: Int. J. Heat Mass Transfer, 5-12, 1149 (1962)

16) Prober, R., et al.: Int. J. Heat Mass Transfer, 6-3, 221 (1962)

17) Sparrow, E. M., et al, : Proc. 3 rd Int. Heat Transfer Conf, 3, 15 (1966)

18) Gill, W. N., et al.: Int. J. Heat Mass Transfer, 8-8, 1135 (1965)

19) Sparrow, E. M., et al.: Trans. ASME, Ser. C, 86-4, 508 (1964)

20) Sparrow, E. M., et al. : Int. J. Heat Mass Transfer, 9-1, 53 (1966)

21) Adams, A. et al.: J. A. I. Ch. E., 12-4, 642 (1966)

22) Carter, L. F, et al.: J. A. T.Ch. E., 10-3, 330 (1964)

23) Hartnett, J. P., et a1.: J. Acro/Space Sci, 27-8, 623 (1960)

24) Torii, K., et al.: Proc. 3 rd Int. Heat Transfer Conf, 3, 34 (1966)

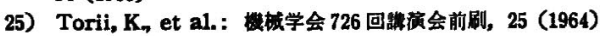

26) Wooldridge, C. E, et al.: AIAA J., 4-11, 2009 (1966)

27) Spalding, D. B.: AIAA J., 3-5, 965 (1965)

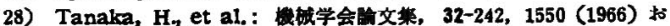
上ぴ J. A.I.Ch.E, 13-1, 194 (1967)

XXII-11 丵丵

はしめに

装置工業の分野でもっとも利用度の高い装䐈の一つに 擋拌槽があるが，云熱操作の面では理論的な体系化が遅 れており不明確な点が多い。機粠の解明といら立場から の文献もきわめて少なく，問題点の所在を明らかにする ことも意味あることと考え全般的な現状の紹介という点 に留意してまとめてみた。

\section{1. ニュートン流体に関する研究}

\section{$1 \cdot 1$ 平均的云繁係数 $\left(\bar{h}_{j}\right)$ を中心とする研究}

実用に供せられている諸相関式はすぺてこれに属する が，翼の種類によって多少異なっている。これら諸式の 適用範囲，使用法飞ついては E. J. Ackley ${ }^{1)}$, F. F.

* 昭和 42 年 2 月 27 日 受理

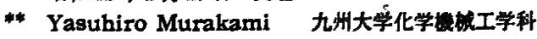

伝 蕉*

$$
\text { 村上 泰 弘** }
$$

Chapman ${ }^{11,12)}$ の紛説に詳しい。伝熱係数は Heat flux を暨温度と流体側温度の代表値差で除して求めるか，こ

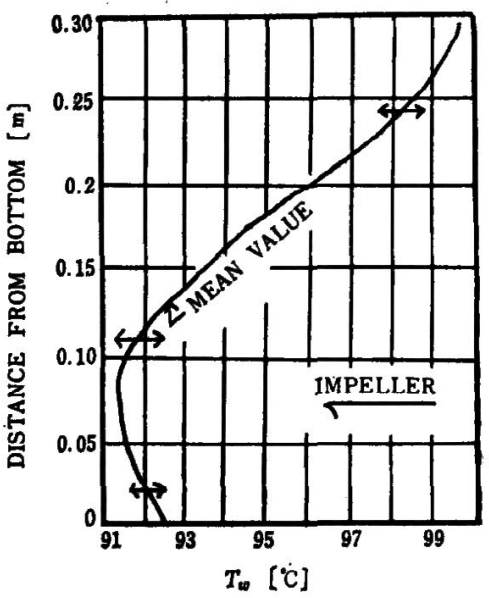

Fig. 1

Wall temperature profile $\left(R e=2.1 \times 10^{5}\right)$ 


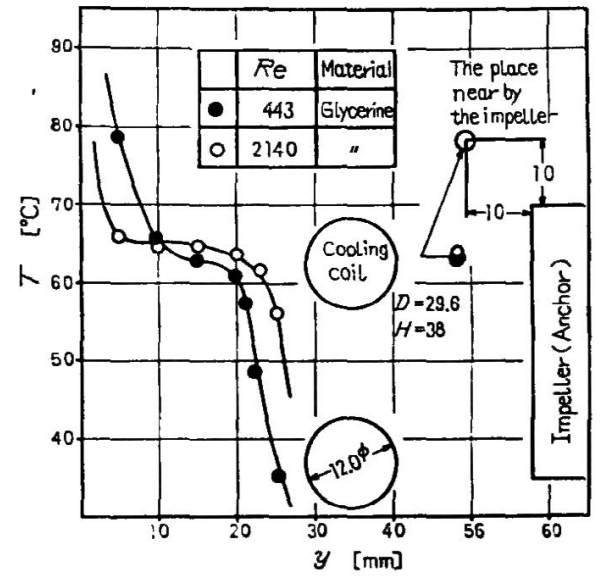

(A)

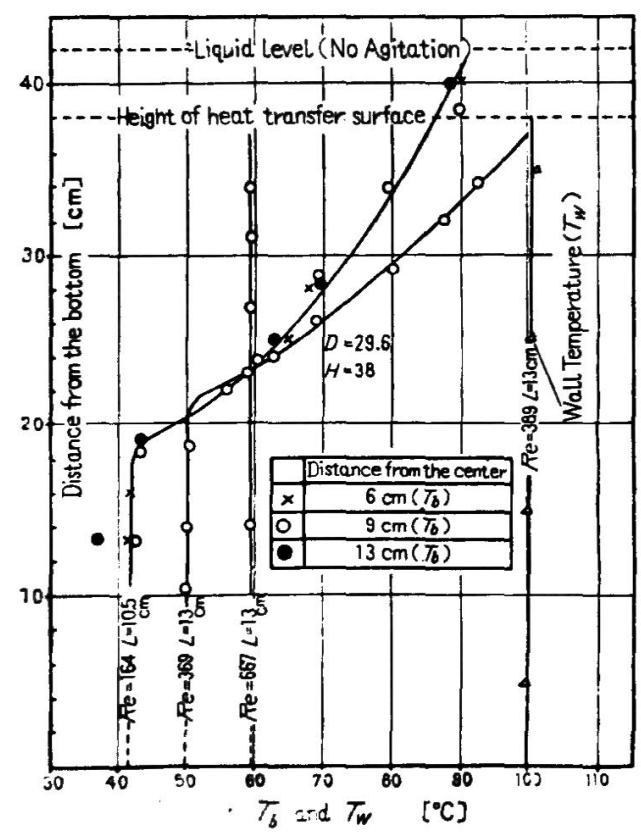

(B)

Fig. 2 An example of measuring temperature profile in the agitated reseel

れらの要因について検討した例は少ない。图1，图2に F. Strek ${ }^{23)}$ ，水科 ${ }^{16)}$ らの壁温度，流体内温度分布の実

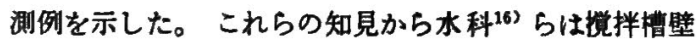
㑡伝熱保数の质移域の問題を明らかにした。また代表的 な各種摚拌翼特性を $(b \sin \theta / H)^{0.15}\left(n_{g}\right)^{0.15}$ なる無次元 項（命却管の場合は $H$ を $H_{\mathrm{c}}{ }^{18)}$ とする）で統一してい る ${ }^{16)}$ 。以上の研究は注とんどすへて乱流域に属するすの であるが，層流域は実用上あまり意味がなく，むしろ掻 き取り型6,7,13,15,20-22)，ドラフト付螺旋型翼192などが熱 移動現象の高能率化には望ましい。今後両者の連続的か つ統一的な現象把握, 邪魔板効果, 冷却 (加熱) 管群の
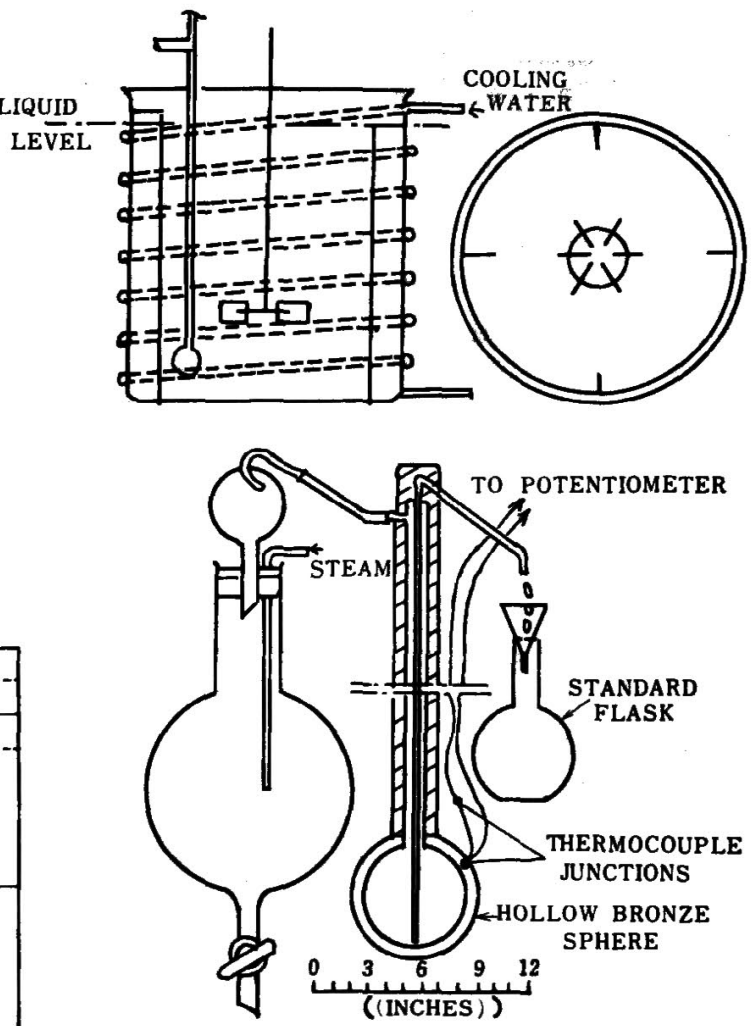

Fig. 3 Mixing vessel and heat-transfer probe
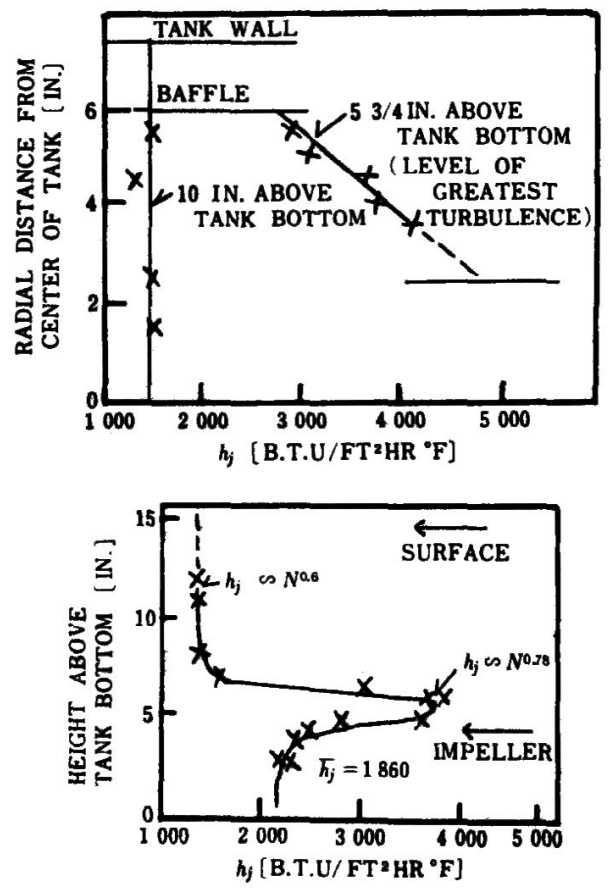

Fig. 4

Point_heat-transfer coefficients in a mixing vessel 


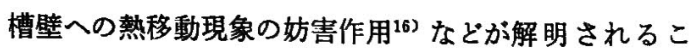
とが必要である。最近 W.T. Appleton ${ }^{3)}$ らは冷却管壁 表面粗さの研究で高 $P r$ 域と低 $P r$ 域について伝熱举動 の差異を論じている。Uhl らの本す参考になる ${ }^{24) 。 ~}$

\section{$1 \cdot 2$ 局所的伝熱俰数 $\left(h_{j}\right)$ の挙動に注目した研究}

擋拌槽伝熱が学問的な体系化使功するか否かはこの 方面の研究にまつところが大きい。P.H. Calderbank ${ }^{9}$ らの研究は示唆に富む内容を有している。図3に実験に 用いた槽，测定用 Probe を，图４亿結果を示す。この Probe は槽中を任意に移動させ, 伀熱量は内部より押出 される凝縮量を実測する。図 4-A は翼近傍の及 $h$ 小 $(L / D)$ の影皘をうけ, 翼より5inch す離れると $(L / D)$ の影翠がないことを示している。至について $(L / D) の$ 影響があまり顕著でないとい5水科ら ${ }^{16)}$ の結果涌じ るものがある。また図 4-Bから翼近傍では回転数依存 性が $h_{j} \infty N^{0.78 \text {, 翼より遠さかると } h_{j} \infty N^{0.6} て ゙} \bar{h}, \infty N^{0.67}$ (1・1 項参照) であることを考え合わせると興味深い。 平板模型に基つく結論 ${ }^{2,4)}$ が $\bar{h}_{j} \infty N^{0.8}$ であることにつ いてす近い将来明確な解答が期待されそうである。

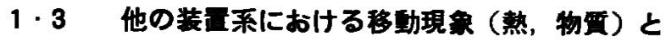 の関係}

P.H. Calderbank ${ }^{10)}$ らは Kolmogoroff 理論上り導び かれる小渦の尺度である下記 (l) と1次渦の大きさの 尺度 $(L)$ (摚拌槽の場合は翼径) 間の距離 $(d)(L \gg d$ $\gg l$ ) の乱流場 (Isotropic Turbulence を仮定) に淤け る速度变動 $U_{(d)}{ }^{2}$ を用いた $R e$ 数を定義し物質・熱移動 係数との相関式を導びいた。すなわち

$$
\begin{gathered}
l=\frac{! \mu_{c}^{3 / 4}}{\rho_{c}{ }^{1 / 2}}\left(\frac{P}{v}\right)^{-1 / 4} \\
\bar{U}_{(d)}{ }^{2}=\text { Const. }\left(\frac{P}{v}\right)^{2 / 3}\left(\frac{d}{\rho_{c}}\right)^{2 / 3} \\
\frac{\bar{U}_{(d)^{2} d \rho_{c}}}{\mu_{c}} \infty \frac{d^{4 / 3} \rho_{c}^{2 / 3}\left(\frac{P}{v}\right)^{1 / 3}}{\mu_{c}}=\left(R e^{\prime}\right)^{2} \\
=\left(\frac{\rho_{c}^{1 / 3}\left(\frac{P}{v}\right)^{1 / 6} d^{2 / 3}}{\mu_{c}^{1 / 2}}\right)^{2 * *}
\end{gathered}
$$

物質移動係数 $k_{L}$ と $\boldsymbol{R e}^{\prime}$ は次の関係にあると仮定し, $k_{L} \operatorname{cs} D_{L}^{2 / 3}$ なる通常の関係を考虑すると $x=1 / 3, y=3 / 2$ となる。

$$
\frac{k_{I} d}{D_{L}} \circlearrowleft\left(\frac{\mu_{c}}{\rho_{c} D_{L}}\right)^{x=1 / 3}\left(\frac{\rho_{c}{ }^{1 / 3}\left(\frac{P}{\nu}\right)^{1 / 6} d^{2 / 3}}{\mu_{c}^{1 / 2}}\right)^{y=3 / 2}
$$

すなわち，熱移動を含めて

$$
k_{L}, \frac{h}{C_{p} \rho_{c}} \operatorname{cs}\left\{\left(\frac{P}{v}\right) \mu_{c} / \rho_{c}\right\}^{1 / 4}\left(\frac{C_{p} \mu_{c}}{\lambda}\right)^{-2 / 3}
$$

* $v \cos L^{3}$ とおくと $(l / L)^{4}=1 /\left(\rho_{c}{ }^{2} P L / \mu_{c}^{3}\right)$ となる。

** $v \cos L, d \cos L$ と技くと $\left(R e^{\prime}\right)^{6}=\rho_{c}^{2} P L / \mu_{c}^{3}$ となる。

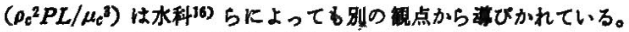
W.S. Askew”) らの手法る水科らの目眼と同じ考え方である。
擋拌槽云熱俰数, 物質移動（固一液系, 液一液系) に 関する既往の実験値は $66 \%$ の偏差で次式でまとめられ た。

$$
k_{L}(S c)^{2 / 3}=\frac{\bar{h}}{C_{p} \rho_{c}}(P r)^{2 / 3}=0.13\left[\frac{(P / v) \mu_{c}}{\rho_{c}^{2}}\right]^{1 / 4}
$$

充填層中を流れる流体の流動損失は次式で示される。

$$
\frac{P}{v}=\frac{\Delta P}{L_{p}} \frac{G}{\rho_{\varepsilon} \varepsilon}
$$

$\Delta P / L$ について Chu の実験式を考虑する。

$$
\frac{\Delta P}{v}=35.4\left(\frac{\mu_{c}(1-\varepsilon)}{d G}\right)^{0.44} \frac{G^{2}(1-\varepsilon)}{d \rho_{c} \varepsilon^{3}}
$$

(7)，(8) 式を（6）式に代入し， $\varepsilon=0.41$ とおくと

$$
J_{D}=0.69 N_{R e}{ }^{-1 / 3^{97}}
$$

となり Fallat らの結果 $\left(J_{D}=0.626 N_{R e}{ }^{-0.322}\right)$ K一致 する。円管内流動については Blasius の式から次式をう る。

$$
\frac{P}{v}=\frac{\Delta P d_{p} \rho_{c}}{L_{p} G^{2}}=0.0396\left(N_{R e}\right)^{-1 / 4}
$$

（10）式を（6）式代入すると

$$
J_{H}=0.058 N_{R e}{ }^{-1 / 3^{9)}}
$$

これは $N_{R_{e}}=2000 \sim 20000$ で Chilton and Colburn の結果 $\left(J_{H}=0.023 N_{R e^{-0.2}}\right) k \pm 12 \%$ で一致する。(6) 式は相当のパラッキを有する相関式であるとはい充, 従 来の回転速度のみを考虑した $R e$ 数 $\left(L^{2} N / \nu\right)$ を用いた 相関式のことく，擋拌系の幾何学的相対関係によらず, $P / v$ が正しく評価されればェネルギー消費形態の同様な 系にはすへて適用可能である点で一般的である。従来頻 用されている擋拌槽の $R e$ 数 $\left(L^{2} N / \nu\right)$ は槽内各部署の 擋拌状態を正しく反映していないことは事実である。今 後の研究課題の一つであるといえる。ンは運動粘度を示 す。

\section{2. 非ニュートン流体に関する研究8, 14,17, 18)}

すへて平均的伝熱係数に基つく相関式である。槽壁側 に対して P. Carreau ${ }^{8)}$ (Turbine), Blanchard ${ }^{14)}$ Б(Paddle), 水科 ${ }^{17)} ら$ (Anchor) の結果がある。たと竞ば Carreau らは次式を求めているが， $N_{R e}{ }^{\prime}, N_{P \tau}$ での見掛 け粘度は異なっており不合理である。

$$
N_{N u}=1.474 N_{R e}{ }^{10.7} N_{P r}{ }^{0.33}\left(\mu_{d w} / \mu_{a}\right)_{a}{ }^{-0.24 / n}
$$

各研究者の結果は擋拌翼す異なり, 流動模型す異なっ ているので簡単に比較できない。冷却管については水 科 ${ }^{18)}$ らの研究がある。以上は擬塑性流体に関するすの であるが塑泩流体については槽壁, 冷却管に関して水 科17.18) らの研究があるのみである。

\section{むす ひ}

最近擋拌槽伝熱に関し基碳的なフプローチが種々行な われつつあることは実用上からす好ましいことである。 
$b$ : 羽根幅, $C_{p}$ : 比熱, $D$ : 槽径, $D_{c}$ : 拡散倸数, $d:$ 分散系粒子径亡た恃距離 $L \gg d \gg l, d_{p}$ : 管径,

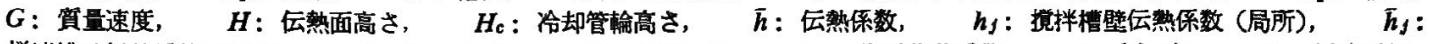

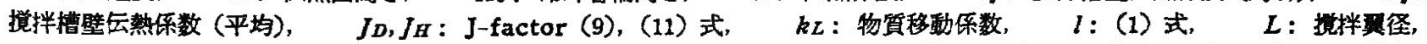
$m$ : Power law 保数, $N$ : 回転数, $n$ : Power law 指数, $n_{p}$ : 拱拌羽根数, $\mid P / v$ : 単位容糟あたり動力, $\Delta P / L_{\mathrm{p}}$ : 単位長あたり王力損失, $\quad P$ : 密度, $\mu$ : 粘度, $\lambda$ : 熱伝尊度, $\quad\left(\mu_{d}\right)_{a}$ : 高速度勾配域平衡粘度

(無次元項)

$N_{N u}=\bar{h}_{j} D / \lambda$ (ヌッセルト数) $, \quad N_{R e}=d_{p} G / \mu_{c}, d G / \mu_{c}, \quad N_{R e}=L^{2} N^{2-n} \rho / \gamma$ (レイルルズ数), $\quad N_{P_{r}}=C_{p}\left(\mu_{d}\right)_{a} / \lambda$ (プラ ントル数), $\quad r=g_{\mathrm{c}} m / \mathrm{s}\left(\frac{6 n+2}{n}\right)^{n}, \quad \operatorname{Pr}, S c:$ ブラントル,シェミット数

(添 字)

$c$ : 連続相, $\quad w$ : 壁面, $\quad b$ : bulk

\section{引用文 韵}

1) Ackley, E. J.: Chem. Eng., 22, Aug. 22, 133 (1960)

2) Andersen, H. E.: Chemie.-Ing.-Techn., 35, 824 (1963)

3) Appleton, W. T. and Brennan, W. C.: Canad. J.Chem. Eng. 44, 276 (1966)

4) Askew, W.S. and Beckmann, R. B.: I. E. C./P. D. D., 4. 268 (1966)

5) Askew, W.S. and Beckmann, R. B.: ibid., 4, 311 (1966)

6) Bott, T.R. and Romero, J. J. B.: Canad. J. Chem. Eng, 41, 213 (1963)

7) Bott, T, R. and Sheikh, M. R.: Brit. Chem. Eng, 9, 229 (1964)

8) Carreau, P., Chareat, G. and Corneille, J.L.: Canad,J. Chem. Eng, 4, 3 (1966)

9) Calderbank, P. H. and Moo-Young, M. B. : Int. Symposium on Distillation P-59 (1960)

10) Calderbank, P.H. and Moo-Young, M. B.: Chem. Eng. Sci., 16. 39 (1961)

11) Chapman, F. F. and Holland, F. A.: Chem. Eng, 12, Janu. 18, 153 (1965)
12) ibid., 72, Feb. 15, 175 (1965)

13) Houlton, H. G.: Ind. Eng. Chem., : 36, 522 (1944)

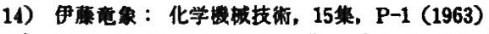

15) Latinen, G. A.: Chem. Eng. Sci., 7, 263 (1958)

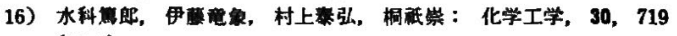
(1966)

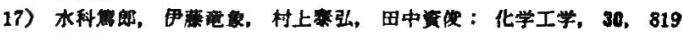
(1966)

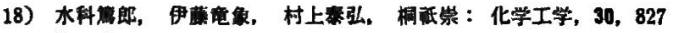
(1966)

19）井田進尚：化学工场, 9, 18 (1965)

20) Skelland, A. H.: Chem. Eng. Sci., 7, 166 (1958)

21) Skelland, A. H.: Brit. Chem. Eng., 3, No. 6, 325 (1958)

22) Skelland, A. H., Oliver, D. R. and Tooke, S.: Brit. Chem. Eng., 7, 346 (1952)

23) Strek, F.: Int. Chem. Eng, 3, 533 (1963)

24) Uhl, V. W. and Gray, J. B, "Mixing Vol. 1". Academic Press (1966)

XXII-12 弿妒

功 刀 雅 長**

筧炬では，然料として重油が広く使用されており，焰 からの伝熱は放射伝熱が支配的であることはよく知られ ている。

Holliday ら"は, 岇素々水素との比 $R=C / H$ か 6.36 ないし 12.57 の範用の然料油について，その焰の放射率 $\varepsilon$ と $R$ との関係を表わす実験式として

$$
\varepsilon=0.282 \ln \frac{R-5.0}{4}+0.002(T-200)+0.484
$$

をえている。ただし $T$ は油の沸点 $\left({ }^{\circ} \mathrm{C}\right)$ である。さら

\footnotetext{
- 昭和 42 年 3 月2 日 受理

* Masanaga Kunugi 京都大等工学部工策化学枓
}

に焰中の煤の量および放射率を湘定し，焰の放射率 $\varepsilon は$ 次の式で与えられることを述へている。

$$
\epsilon=1-e^{-0.0025 L C}
$$

ただし，Lは焰の厚さ $(\mathrm{cm}), C$ は煤の量 $(\mathrm{mg} / \mathrm{l})$ である。

案炉では, 重油バーナーとしては, 空気あるい性蒸 気の高速によって油を籍化する形式のバーナーが比較的 よく使用されているので, Hubbard ${ }^{22}$ はこの形式の重油 バーナーを使用し，バーナーのスラスト，雺化用空気 量，バーナー・チップの䄼造，雺化用流体の種類などの 